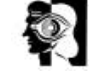

columns

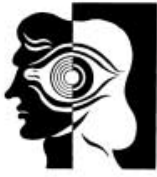

\title{
the columns
}

\section{correspondence}

\section{Drug use on in-patient wards}

Phillips \& Johnson reported on the very high prevalence of drug use among those with psychosis on psychiatric wards in two Boroughs in inner London (Psychiatric Bulletin, June 2003, 27, 217-220). During 2002 , on one of the wards included in their study, we routinely collected urine specimens for drug screening from all new admissions. Data from 69 admissions suggested that drug use was even higher in those with non-psychotic illnesses.

There is a positive way of looking at this problem. One obvious but frequently overlooked reason for the high prevalence of substance misuse among in-patients is simply that many clinicians look to admit heavy users because they believe that doing so provides them with an opportunity to detoxify, or at least cut down substantially, on their drug use. More research is needed to establish to what extent this is successful but, on the whole, clinical impressions would suggest that it is. Users of crack cocaine with psychosis in particular seem to benefit from a period of abstinence enforced, or partially enforced, by their admission.

For this reason, continuing drug use by an in-patient should not be seen as an unreserved failure, especially if it is conti nuing at levels lower than it was prior to admission. Even when the drug use is relatively unchanged, the admission can be viewed optimistically, as an opportunity for clinicians to provide counselling to the in-patient in a way that is rarely possible in the community.

PHILLIPS, P. \& JOHNSON, S. (2003) Drug and alcohol misuse among in-patients with psychotic illnesses in three inner-London psychiatric units. Psychiatric Bulletin, 27, 217-220.

Rupert White, Consultant Psychiatrist, Cornwall PartnershipTrust, Bodmin Hospital, Boundary Road, Bodmin, Cornwall PL3120T

\section{Suicide bombers and institutional racism}

I was delighted with the recent stand taken by the College President on institutional racism in British psychiatry (Psychiatric Bulletin, April 2003, 27, 155). There was a similarly strong reaction to an article by Hickling and Hutchinson (Psychiatric Bulletin, March 1999, 23, 132-134), on 'Roast Breadfruit psychosis', which though appearing on the surface to be harmless and scientific, had the inevitable effect of causing significant offence to a specific minority group by equating the normal phenomenon of identity confusion in this racial group with psychosis or madness.

I was shocked, therefore, to read Dr Gordon's piece on the suicide bomber (Psychiatric Bulletin, August 2002, 26, 285-287), and the more recent editorial in the British Journal of Psychiatry on suicide terrorism (Salib, 2003). Attempting at all to debate and medicalise such an obviously political issue is, in my view, an example of the denigration by association of specific minority groups. Discussing psychiatric aspects of suicide bombers with madness and such insinuations is offensive. In the article, Dr Gordon quite skilfully weaves a weakly-disguised thread of associations linking the suicide bomber, through terrorism, and a focus on the Arab and Muslim origins of suicide bombers, to the horror of 11 September, weapons of mass destruction and poten tial global destruction. I would contend that such views, even if offered in the form of scientific or philosopical debate, are aggressive and racially provocative, insofar as they inevitably leave the minority group readership with a countertransference of having been abused or undermined.

One cannot help but question the role of the Bulletin and its naïvety in allowing itself to be unwittingly 'hijacked' in this way. After all, the issue of suicide bombers, or Roast Breadfruit psychosis, can hardly be said to be of significant relevance to everyday clinical practice. Indeed verbal denigration has been identified as the initial stage in a behavioural pathway leading to violence against minority groups (Hayes, 1994). I wonder if perhaps the publication of this and similar articles reflects something of an increasingly blatant right-wing agenda, which is becoming visible not just in the UK, but across Europe.

Dr Shooter is right. Institutions have a collective responsibility to uphold, and publish those values and opinions that are wholesome and non-discriminatory. And so have all of us.

HAYES, N. (1994) Foundations of Psychology. London: Routledge.

SALIB, E. (2003) Suicide terrorism: a case of folie plusieurs? British Journal of Psychiatry, 182, 475-476.

Deji Odelola, Consultant Psychiatrist, Birch Hil Hospital, Rochdale, Lancashire OL12 9QB

\section{Editor's reply}

I could not disagree more. I am very proud to have published the two papers $\mathrm{Dr}$ Odelola refers to. The first, by Hickling \& Hutchinson, was interesting, provocative and well written. It was accompanied by a series of informative critical commentaries. The result was, in my view, a comprehensive exploration of a controversial topic The article by Gordon was, in my view, a well-balanced and self-critical review of a highly-topical subject.

The Bulletin's aim is not to publish a 'wholesome' journal. Instead, we want to be a vehicle for education, discussion and vigorous debate. This function cannot be achieved by the type of censorship suggested by Dr Odelola. There has been no 'hijacking' (to use Dr Odelola's unfortunate metaphor) by a right-wing agenda. We are simply attempting to reflect the full range and excitement of modern clinical psychiatry.

Tom Fahy 